\author{
Susanne Schwarzl \\ MCI Management Center Innsbruck \\ Austria \\ schwarzl.s@hotmail.com \\ Monika Grabowska \\ Wroclaw University of Economics \\ Poland \\ monika.grabowska@ue.wroc.pl
}

Abstract. It is well-known that traditional (offline) marketing strategies are already widely used by the companies around the world and there are almost no new options for fostering competition. And here comes online marketing with almost unlimited posMay, 2015 sibilities and options. This paper focuses on the growing importance of online marketing, including research of the state of the art through analysis of the data provided by numerous surveys. It also contains brief description of the online marketing itself, basic strategies on the internet nowadays and the answer to the question: How it is possible to get new customers while keeping the old ones?

DOI:

Keywords: online marketing, customer behaviour, customer journey, marketing research

JEL Classification: D03, J48, M31

\title{
INTRODUCTION
}

American Marketing Association defines a brand as "a name, term, design, symbol, or any other feature that identifies one seller's good or service as distinct from those of other sellers. The legal term of brand is trademark". Brands are seen as complex social phenomena which have a huge value for companies and customers. A brands' goal is identification of a product and its producer as to differentiate the offering in a valued way and command margin (Mooradian et al., 2012; Herget et al. 2015).

On the contrary, "customer journey" describes the "tour" a customer goes through before purchasing, ordering or asking for a certain product or service of a company. It shows what kind of touch points are responsible for a potential consumer to finally end up on a company's website. This journey can last a few hours or even days (Mattscheck, n.d.). The so-called touch points are classy advertisements as TV or radio spots, banners but also online marketing measures or mouth-to-mouth advertisements where customers get the possibility to get in touch with a company (Mattscheck, n.d.). 
As said before, the world of online marketing is a new one for that reason there are many different definitions and projections. It is not clear where to make the difference between online marketing and internet marketing. Very often online marketing is also equalised with "Online advertising", "Performance marketing" or "Search engine marketing", although this terms do not have an equal meaning (see e.g. Constantinides, 2002; or Lammenett, 2014). Internet marketing is a target-orientated use of the internet tools like WWW or email. Here the major constituent is an internet page (Naik and Raman, 2003).

On the other hand online marketing implies packages of measures, which should lead internet users to certain webpages to buy or order certain products or services. So web presence is the main object of online marketing. In addition also arrangements outside the internet are included in online marketing, e.g.: a banner on a plane which shows an uniform resource locator (URL) (Lammenett, 2014).

Online advertising means to show banner from the company on the webpage from another company. What started with ordinary banners became more developed nowadays. Beside banners also layer-ads, interstitials and videos are used to get users' attention on foreign websites (Naik and Raman, 2003). Performance marketing consists of measures whose object is to get a measurable reaction of costumers, e.g.: click on a banner, purchase a product or registration on a website (Springer Gabler Verlag, n.d.). The main goal is a high level of interaction with customers, to influence their courses of action (Kozinets, 2002; or Lammenett, 2014; Codourey, 2013). Search engine marketing is a part of online marketing and includes all measures to acquire customers on basis of online searching tools. Because of Google's way to present search results, search engine marketing became more complex (Kozinets, 2002).

This paper contains five blocks. At the beginning we shall research key facts and figures describing the state of the art of online marketing and provide relevant insights for better understanding of its growing role. Our research was performed using the method of analysis and synthesis of the data provided by the CMO Council, WebDAM, iContact, ContentPLUS and other sources. Afterwards, the most important terms were explained to secure a detailed and comprehensive adaption of the topic. Thirdly, customer behaviour will be clarified on the consumer decision making process. Fourthly, different strategies concerning online marketing will be explained. Fifthly, a brief overview of customer journey will be given and illustrated with the help of a simple example at the end of this paper.

\section{ONLINE MARKETING: STATE OF THE ART}

One of the key indicators of online marketing development is the growth of the number of internet users. For nearly 25 years public is having access to the internet. Since then it has been a continuing development and innovating process. People are able to do nearly everything with their computers e.g.: shopping, booking, doing researches, communication, etc. The following graphic shows the enormous increase of internet users since 1995: 


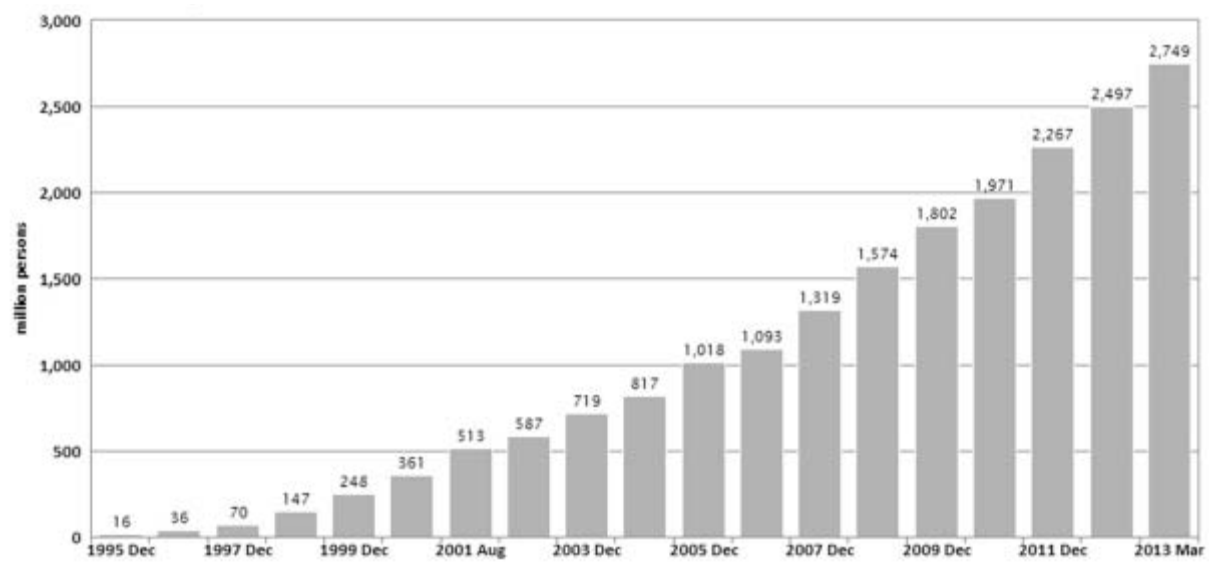

Diagramm 1: World Internet Usage Growth

Source: Mahajan (2014).

These numbers demonstrate the importance of internet nowadays and necessity for companies to be present on this certain market - the online market. However, mentioned figures describe the potential of online marketing strategy, its growing audience. But is the online marketing efficient? What are pros and cons? In order to answer such questions and to provide the reader with better insights regarding online marketing in the text below we shall analyze results of the surveys conducted by the CMO Council, WebDAM, iContact, ContentPLUS and other companies.

According to the data collected by the CMO Council $71 \%$ of internet users are more likely to purchase from a brand that they are following on a social networking site such as Twitter or Facebook. Moreover, the majority of marketers (59\%) are using social media for 6 hours or more each week. Additionally, online marketing generates 3 times as many leads as traditional outbound marketing, but costs $62 \%$ less. Herewith, marketing professionals are 50\% more likely than consumers to like a brand on Facebook, 400\% more likely to follow brands on Twitter, $100 \%$ more likely to make a purchase as a result of seeing something on Facebook, and 150\% more likely to make a purchase as a result of a tweet. But still, $83 \%$ of consumers reported that they have had a "bad experience with social media marketing, consequently there is a room for improvement.

Pursuant to the data collected by WebDAM the following are the key facts on the online marketing:

- in 2014 the marketers spent approximately 135 billion of dollars on new online marketing collateral.

- $78 \%$ of CMOs think that online marketing is the future of the marketing.

- Internet advertising will make up nearly $25 \%$ of the entire advertising market by 2015 .

Surveys of iContact and ContentPLUS provided us with the following insights:

1. Average return on online marketing investment: $\$ 44.25$ for every dollar spent;

2. Consumers who are involved in online marketing spend $83 \%$ more when shopping, make orders $44 \%$ larger and $28 \%$ more often;

3. Personalized online marketing improves click-through rates by $14 \%$, and conversion rates by $10 \%$;

4. Blogs are $63 \%$ more likely to influence purchase decisions than magazines.

As we can see, online marketing is revolutionizing the way in which companies compete between each other. Marketers around the world have realized the importance of online marketing and its advantages 
compared to traditional marketing. Online marketing has a lot of pros, namely: it can reach customers more effectively; it is cost effective; results can be reliably measured, it can be personalized, etc. However, it has also a lot of cons, the most significant of which is too high level of competition. Therefore, companies should clearly understand what they have to do and how they have to do it. Thus, in the text below we will provide information necessary for development of efficient online marketing strategies.

\section{CUSTOMER BEHAVIOUR}

One of the most important topic companies should focus on is the customer behaviour. It is necessary to understand how customers evaluate and make decisions to segmenting, targeting, positioning and to developing an effective marketing mix.

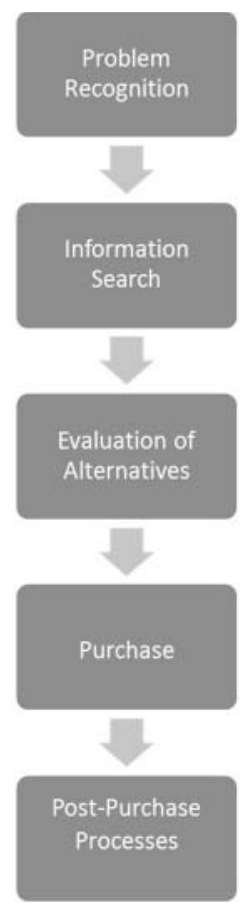

Diagramm 2: Consumer Decision Making Process

Source: Own results based on Mooradian (2012).

It must be said that there is a difference between ultimate consumers and organizational buyers (especially businesses). In this paper the focus is on the behaviour of ultimate customers (Springer Gabler Verlag, n.d.). Before a consumer decides to buy a certain product or service he or she goes through five different stages which are summarized in the so called "consumer decision making process" which will be explained below: 


\section{Stage 1: Problem Recognition:}

A consumer's "need" is the fundamental reason for making a buying decision. All people do have needs because these are basic human requirements. The goal of humans is to satisfy these needs. Abraham Maslow distinguished between different highnesses of needs in a hierarchical structure. He said that lower-level needs are more compelling and they are prior over higher-level needs. The following graph shows Abraham Maslow's pyramid in which he organized human needs (Mooradian et al., 2012):

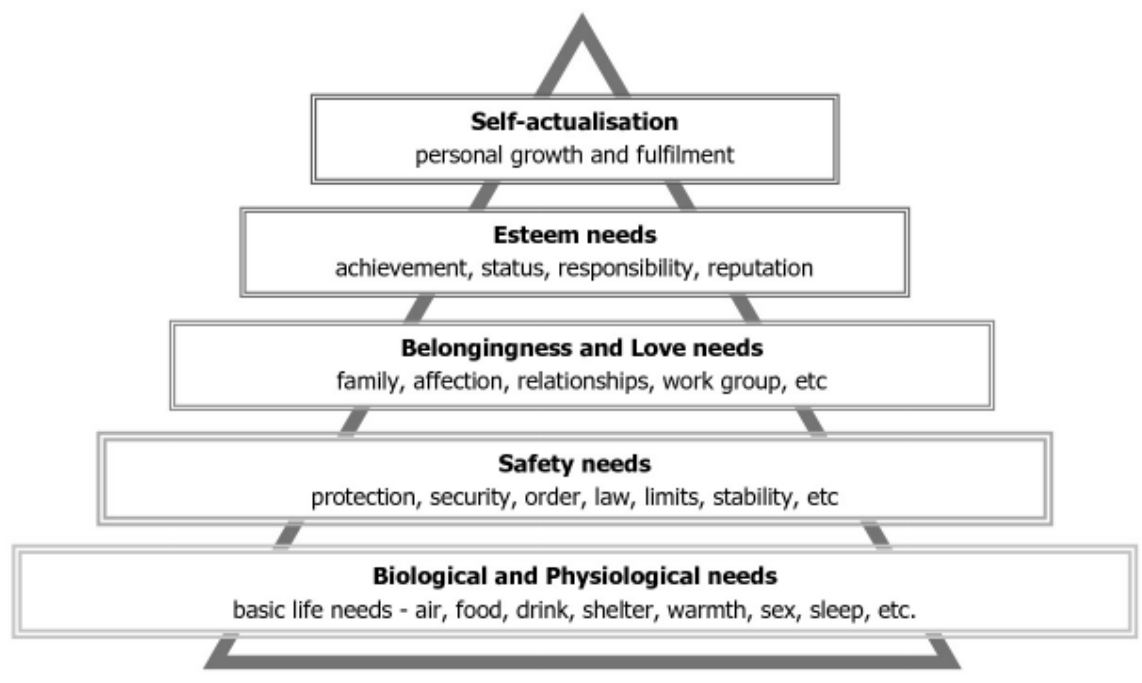

Diagramm 3: Pyramid of Abraham Maslow

Source: Lesley and Jade (2014).

Problem recognition is generally seen as a form of "gap analysis". It means that the consumer realises that there is a need when they recognize, consciously or subconsciously, that there is a disparity between the way things are and the way they would like to be (Mooradian, 2012).

\section{Stage 2: Information Search:}

Before purchasing consumers want to inform themselves about certain products or services. The question of how much time an individual spends on searching information depends on the so called involvement. Involvement expresses the degree of importance and relevance a consumer sees in a product or purchase. It is also explained as the motivation to pay attention to a product or buying decision. Understandably a consumer pays more attention in buying a car than in repeat purchases as laundry detergent or soda. So purchasing a car means high involvement whereas buying a washing detergent means low involvement (Mooradian, 2012).

\section{Stage 3: Evaluation of Alternatives:}

Consumers form "attitudes" toward products and they influence purchase behaviour. These attitudes represent summaries whether something is pleasant or unpleasant for example. So consumers evaluate based on their formed attitudes whether the attitude is a good or bad thing for the product to have. Attitudes can 
be for example power, comfort, liability and/or high price. This causes a very hard reflection about certain purchases. But additional there exists also another system besides the so called "rational thinking" or "cognition". Consumers also buy products based on individual "feelings" or "emotions". Both systems interact and influence each other and for a company these are essential in understanding consumers' way to respond to marketing actions. This leads us to two important ideas, which support the understanding of how consumers evaluate alternatives: brands and costumer value (Mooradian, 2012).

\section{Brands:}

Consumers are faced with an immoderate flood of marketing information each day. Because of that they stablish habits to make their decisions. Brands are the most common guide for consumers in the market place. They simplify decision making because of connecting prevailing and future decisions to experiences and satisfaction from the past and they also offer reassurance. For short, brands communicate more complex information in simplified ways (Mooradian, 2012).

\section{Consumer Value:}

Easily said consumer value illustrates the balance of the "get" and the "give" which means the ratio of consumers' benefits compared with all the costs of a purchase of a certain product or service. Here costs include monetary costs, time and effort (Mooradian, 2012).

Summarized knowledge about brands and consumer value are essential for developments of products as well as for development of communications programs to position the product and convince people to think about a product in a company's favoured way (Peresadko et al. 2014; Mooradian, 2012).

\section{Stage 4: Purchase:}

After evaluating alternatives there are two more questions for consumers concerning purchases. They must decide when and where they are going to buy. This "point-of-purchase" is a very important one despite of their importance these decisions are made very quickly. That means making such a decision does not last longer than three to six seconds and it happens mostly at the store (Mooradian, 2012).

\section{Stage 5: Post-Purchase Processes:}

Many companies are interested in long term relationships with their customers. A requirement for this is to understand the so called "post-purchase-process". This means a company needs to understand for example how a consumer uses a product or how long products are used, how feelings of satisfaction or dissatisfaction are formed, and a very important question - why or why not does a consumer become loyal.

This stage shows that besides persuading consumers to purchase a company's product companies are also concerning about how consumers create values for these products, about when and how often products are used until the ultimate disposal. This progress is called "customer-value chain" and shows highly important information concerning products' innovations and how to change customers' behaviour (Mooradian, 2012). 


\section{ONLINE MARKETING STRATEGIES}

\section{Affiliate Marketing:}

Online affiliate Marketing was created in 1997 at a cocktail party. A young lady asked Jeff Bezos (founder of Amazon) if he would like her to promote some of his books on her website for a commission payment in return.

The model of affiliate marketing was not an invention these days because it already existed in offlinebusinesses. A partner who is called affiliate promotes products or services from another company which is called merchant (Lemmenett, 2014). Affiliates put for example banners or links of the merchant's website on their own websites to acquire customers (Birkner, 2012). Now there are three different types of how affiliates get commissions. The amount of it is usually declared individually between affiliate and merchant:

1. Pay per click: If a customer clicks on the provided link or banner on the affiliate's website and buys a product of the merchant the affiliate receives a certain commission.

2. Pay per lead: Here the affiliate gets a commission for each person who fills out a web based form with his contact information (mostly e-mail address). Payments of commission can also depend on the price of the sold product or service which brings us to the third type:

3. Pay per sale: the affiliate earns a certain percentage of the products' price (Lemmenett, 2014).

It is also very common to arrange mix types which means affiliates get a commission per click, for example 3 cents, and additionally 5\% of the sale (Lemmenett, 2014).

Greg Shepard, CEO of Affiliate Traction, said that affiliate marketing enables retailers to save more money on advertisements for sales than they would do for traditional online advertisements. He also mentioned that "You only pay when the sale is made ... On top of that, you only pay for the sales that came through (and) you pay 30 days after the sale. Affiliate marketing ... frees up more money for advertising." (Birkner, 2012).

\section{E-Mail Marketing:}

This strategy means to contact customers directly with e-mails. It is a very popular strategy because of saving costs. This kind of e-mail is usually personalised and it consist of the company's brand, a message and a link which guides the customer to the website of the company. More common are e-mails which also show one or more pictures about the promoted product and a connection to the company's Facebook page to support social media marketing as well (Lemmenett, 2014).

There exist different main types of e-mail marketing as I will explain briefly now:

1. Stand-alone-campaign: It is also called E-mailing and the main character of it is that these e-mails normally have a certain retention period. It is used mostly to promote new products or products for one season. So one or more e-mails comprise the same product.

2. Newsletter: The main reason behind a newsletter is to support customer loyalty. They consist of useful information for costumers and are sent to them at least once a month. A disadvantage about newsletters is the constant effort for a company because newsletter always have to be up-to-date so a company should initiate a professional e-mail marketing tool (Lemmenett, 2014).

Companies have to face the problem that because of the volume and frequency of solicitation e-mail users see no value in receiving these messages. Additional spam filters complicate e-mail marketing for companies because these filters cannot distinguish between requested and unrequested e-mails. This leads to a flooding of spam e-mails (Gopal et al., 2006). While 2002 worldwide 2.4 billion spam mails per day were counted in 2011 the number increased to 200 billion spam emails (Trend Micro, 2011). 


\section{Keyword-Advertising:}

This strategy means to put paid banners on results pages of search engines. Goto.com was the first company which had used this strategy in the year 1998. 2002 Google copied it and created the foundation of its contemporary success (Lemmenett, 2014). Keyword-advertising became more meaningful in the world of online marketing for companies which was proven in 2008 by a survey from INTERNET WORLD Business which says that at this time $45.9 \%$ of all interviewees did find a new online shop while using a searching engine (Internet World Business, 2008).

\section{Online Advertising:}

Online advertising is one of the oldest strategies in the online world. The first banner was placed in 1994. Today online advertising includes besides banners many different types of advertisements for example videos. It is said that in the year 2012 online advertising was the most used medium for advertising after TV spots. Because of the decreasing prices and increasing quality of videos this kind of online marketing gets more and more popular for companies. Also the fact that about $40 \%$ of internet users like watching online video advertisements encourages companies to present their brands via videos. Surveys also say that representing a company's brand in a video improves customers' apperception of brands (Lemmenett, 2014).

\section{CUSTOMER JOURNEY}

After a consumer's purchase it is very hard to define which advertising medium was the crucial one for the final purchase. It is important for a company to know which mediums are worth to keep or to invest (Bockhorni, n.d.).

Before, analysis tools like the so called First-Click-Winner or Last-Click-Winner were used. That means only the first advertising medium which was clicked on or the last one has been seen as the crucial medium. Nowadays it is clear that every single medium a consumer passes while his or her journey has a necessary influence on consumers' behaviour. A customer gets through the following phases before making a decision: attention, interest, desire and action.

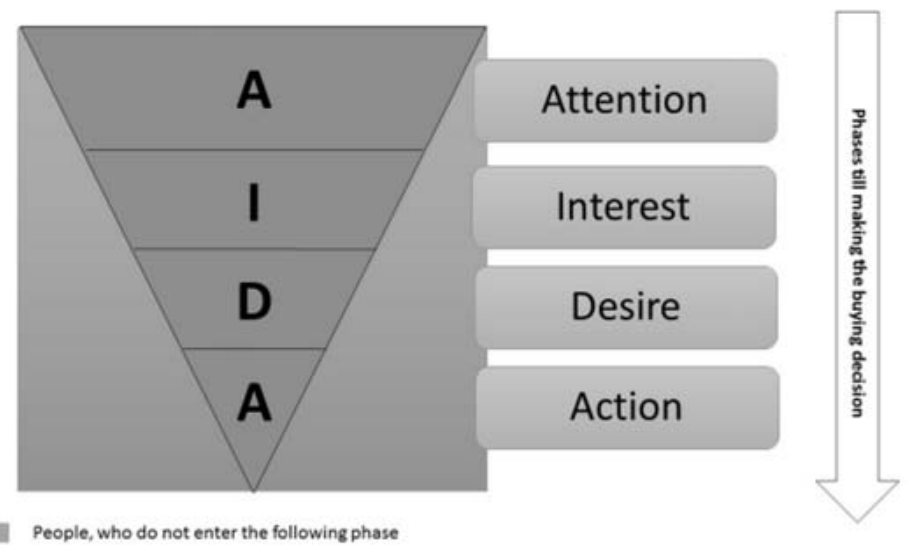

Diagramm 4: AIDA Modell

Source: Own creation based on Bockhorni (n.d.). 
On the basis of the following example these phases are demonstrated and explained:

A potential buyer received a newsletter with information about a high quality coffee machine from the company "XY". This company also invests in search engine optimization. For this reason the potential buyer found the website of company "XY" while searching for the coffee machine. The appealing representation of the product details there aroused the potential buyer's interest definitely. Hence he looked for information about the coffee machine in evaluation forums. The positive assessments there strengthened his buying decision. He also discussed the purchase of the coffee machine with his family. They did some researches in the internet to get some additional information about the coffee machine and the company "XY". They clicked on the search engine advertisement and attained to landing page of the company "XY". Finally this website convinced also the rest of the family so they bought the coffee machine (Bockhorni, n.d.). The interaction of advertising mediums:

- First, the newsletter attracted the attention of the potential buyer.

- The traceability in the search engines and the appealing representation of the product details aroused interest.

- The positive feedbacks in the evaluation forums and the consultation of the family confirmed the buying desire.

- The search engine advertisement and the following landing page brought the potential buyer to the action - the purchase.

This simple example shows clearly that optimization and budgeting of marketing channel based on First-Click-Wins and Last-Click-Wins would lead to enormous faults. Assuming an optimization based on the Last-Click-Wins process in the example, there would be no money left for newsletters because the company would invest this money into search engine advertisements. Nevertheless without the newsletter there would had been no purchase. Following the Last-Click-Wins process the very important function of the newsletter would be dropped away.

Analysis of marketing campaigns is a very complex topic but there exist so called web controlling tools which support these kinds of analyses. Acquired results contain huge potential concerning selection and prioritization of online marketing measures (Bockhorni, n.d.).

\section{CONCLUSIONS}

Online marketing offers an enormous amount of possibilities for companies. It is an evolving world which is why constant development of strategies is necessary. It is much easier for customers to find substitutes from competitors on the internet because of the minimal effort a person has to make to get to another website. Every internet page is full of different kinds of touch points as advertisements and offers which makes it hard for companies to guide potential buyers to a certain website without "losing" them through their way of the internet.

This is exactly why the fundamental understanding of consumers' behaviour is so important. Regardless in which world - online or offline - customers nearly behave the same way. First step is always to catch customers' attention. There are just different types of strategies which are used to get in touch with a certain target group. Which strategies are used at the end depends on the way potential buyers do behave and how a company is able to understand these actions. Nowadays it seems to be indispensable running a business without any online presence because figures show that the trend from consuming in shops goes in the direction of online consuming. 
Therefore every company should have at least one online department which is responsible for the company's web presence. It has to be conformed to the environment and updated as often as possible to reach the maximum of customer loyalty also in the continuous developing online world. So a main goal for companies is to create a clear defined brand which represents companies' values and strengths and catch potential buyers' and loyal consumers' attention offline as well as online. This interaction of both worlds enables a maximum outcome for a company concerning monetary as well as un-monetary profit.

\section{REFERENCES:}

Birkner, C. (2012). The ABCs of Affiliate Marketing, in: Coreconcepts, Marketing News

Bockhorni, Markus, (n.d.), Customer Journey optimieren - Touchpoint-Analyse im Multichannel-Marketing; URL: http:// www.onlinemarketing-praxis.de/web-controlling/customer-journey-optimieren-touchpoint-analyse-im-multichannel-marketing (30.11.2014).

Codourey, M. (2013). The Public Handshake, the Pushed Gossip and the Healthcare Marketing, Economics and Sociology, Vol. 6, No 2, pp. 11-27. DOI: 10.14254/2071-789X.2013/6-2/2.

Constantinides, E. (2002). The $4 \mathrm{~S}$ web-marketing mix model. Electronic Commerce Research and Applications, 1(1), 5776.

Gopal, R. D., Tripathi, A. K., \& Walter, Z. D. (2006). Economics of first-contact email advertising. Decision Support Systems, 42(3), 1366-1382.

Herget, J., Petrů, Z., Abrhám, J. (2015), City branding and its economic impacts on tourism, Economics and Sociology, Vol. 8, No 1, pp. 119-126. DOI: 10.14254/2071- 789X.2015/8-1/9.

Kozinets, R. V. (2002). The field behind the screen: using netnography for marketing research in online communities. Journal of marketing research, 39(1), 61-72.

Lammenett, Erwin, (2014), Praxiswissen Online-Marketing, Springer Gabler.

Mahajan, A. C. (2014). The Growth In Internet And Telecom Users In India During Q2 2014 Disappoints, in: Dazeinfo, URL: http://3.bp.blogspot.com/-9pwPOHp73s4/UvI_xVqqyDI/AAAAAAAAAnA/BHGuT-hFODc/s1600/1. png (30.11.2014).

Mooradian, T. A., Matzler, K., Ring, L. J., (2012). Strategic Marketing, Pearson Education

Mattscheck, Markus, (n.d.), Onlinemarketing Praxis: Customer Journey, URL: http://www.onlinemarketing-praxis.de/ glossar/customer-journey (30.11.2014).

Naik, P. A., \& Raman, K. (2003). Understanding the impact of synergy in multimedia communications. Journal of Marketing Research, 40(4), 375-388.

Peresadko, G., Pidlisna, O., Olefirenko, O., Karpishchenko, O. (2014). Marketing Researches of Social Communication Forms in the Dinamics of Human Development, Economics and Sociology, Vol. 7, No 1, 2014, pp. 217-227. DOI: 10.14254/2071-789X.2014/7-1/19.

Springer Gabler Verlag (Herausgeber), Gabler Wirtschaftslexikon, Stichwort: Performance Marketing, online im Internet: http://wirtschaftslexikon.gabler.de/Archiv/576005962/performance-marketing-v3.html.

Trend Micro, 2011, Spam in Today's Business World, URL: http://www.trendmicro.com/cloud-content/us/pdfs/securityintelligence/reports/rpt_spam-trends-in-business-world.pdf (01.12.2014). 